\title{
Notes on the vocalizations of Canary-winged Finch (Melanodera melanodera)
}

\section{Peter Boesman}

In the following we briefly analyze and compare voice of the two races of Canary-winged Finch (Melanodera melanodera). We also try to quantify the extent of any vocal differences using the criteria proposed by Tobias et al. (2010), as a support for taxonomic review. We have made use of sound recordings available on-line from Xeno Canto (XC) and Internet Bird Collection (IBC).

A comparison of song of both races, illustrated with sonograms:

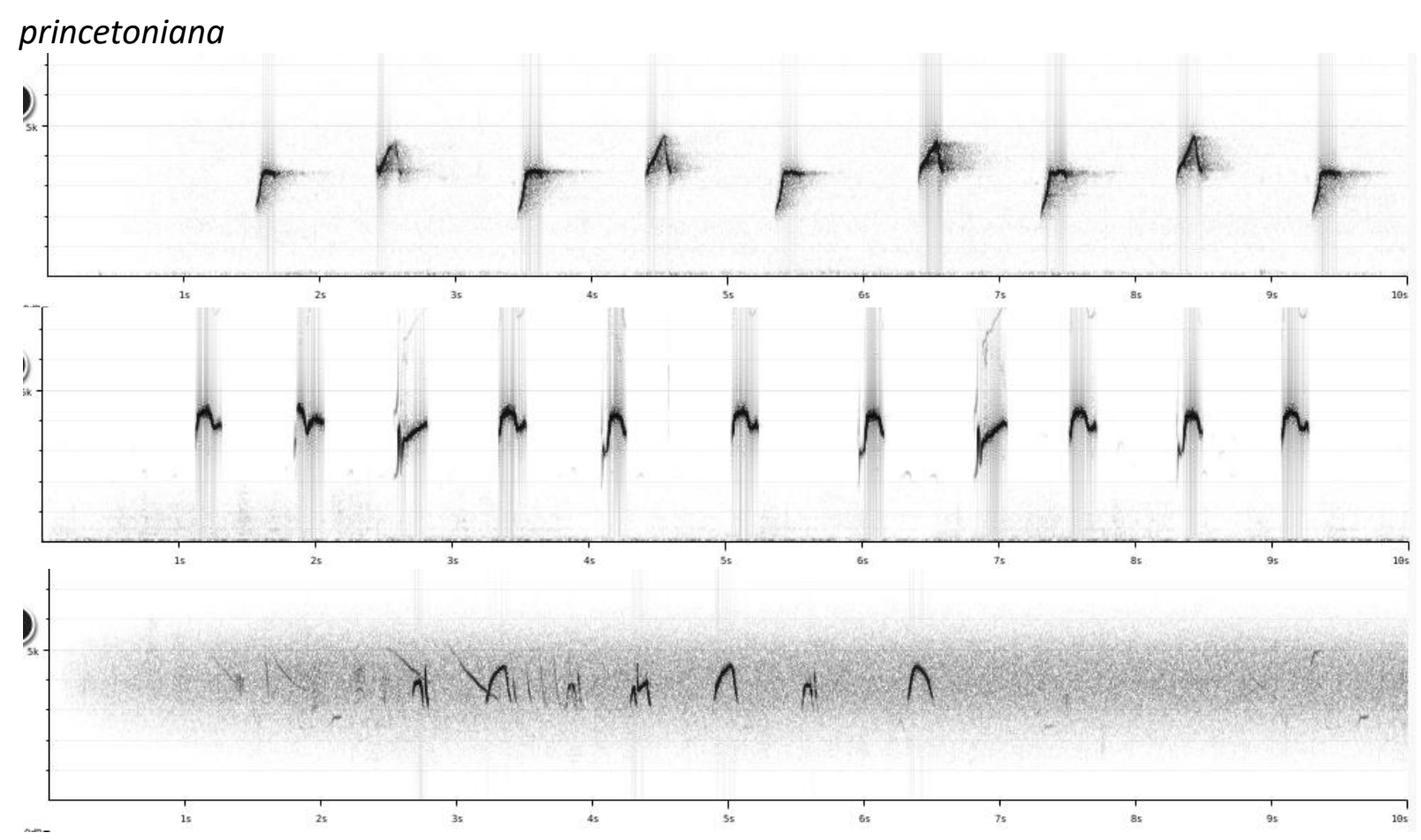

nominate

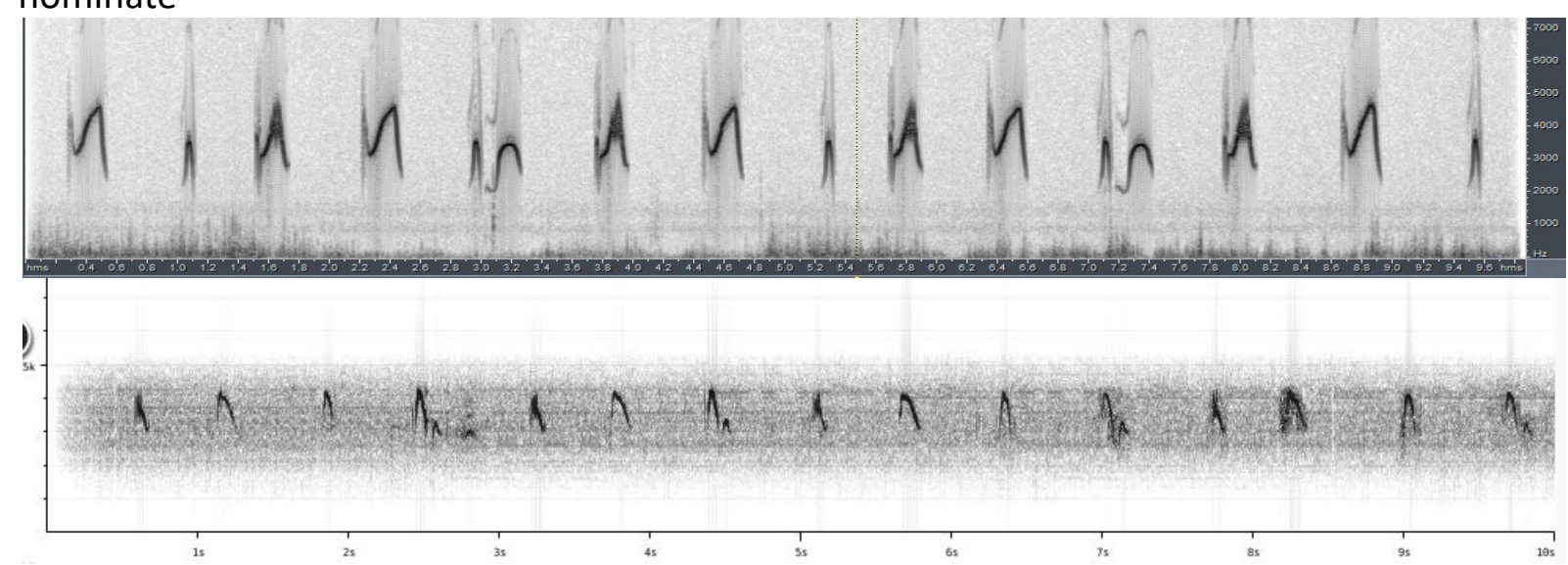



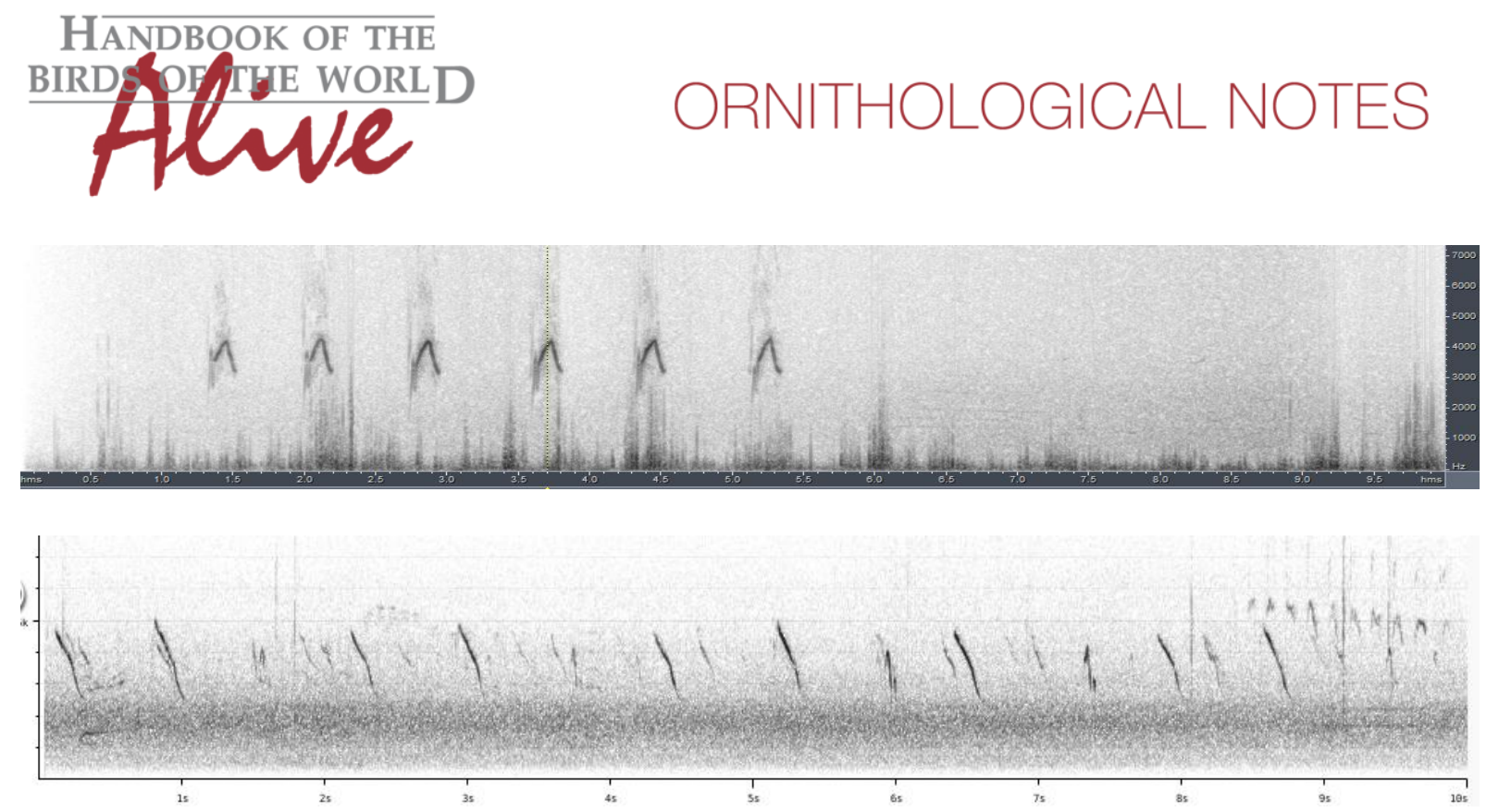

There are only a few recordings of song available for each taxon.

Song of both races is a leisurely delivered sequence of single melodious notes, typically a subphrase of 2-3 different notes repeated for a while.

In full song, pace of princetoniana apparently slightly slower than nominate ( $1-1.2$ notes/s vs $1.4-1.5$ notes $/ \mathrm{s}$ ), but more recordings are needed to establish whether this is a constant diagnostic feature.

This note was finalized on 30th June 2016, using sound recordings available on-line at that moment. We would like to thank in particular the sound recordists who placed their recordings for this species on XC and IBC: Alvaro Jaramillo, Laurent Demongin, Bernabe Lopez-Lanus, Michele Peron, Fabrice Schmitt, Andrew Spencer and Sofia Wasylyk.

\section{References}

Tobias, J.A., Seddon, N., Spottiswoode, C.N., Pilgrim, J.D., Fishpool, L.D.C. \& Collar, N.J. (2010). Quantitative criteria for species delimitation. Ibis 152(4): 724-746.

\section{Recommended citation}

Boesman, P. (2016). Notes on the vocalizations of Canary-winged Finch (Melanodera melanodera). HBW Alive Ornithological Note 390. In: Handbook of the Birds of the World Alive. Lynx Edicions, Barcelona. (retrieved from http://www.hbw.com/node/1253579 on 1 December 2016). 